\title{
Visões plurais em um único olhar A experiência fotográfica de Marcel Gautherot, 1940-1960
}

\begin{abstract}
Ana Maria Mauad ${ }^{1}$
Resenha de: ANGOTTI-SALGUEIRO, Heliana (Org. e Ed.). O Olho fotográfico, Marcel Gautherot e seu tempo. Textos de Heliana Angotti Salgueiro, Lygia Segala e Olivier Lugon. São Paulo: FAAP, 2007, 408 p., ilust. Edição bilíngüe português-inglês.
\end{abstract}

A fotografia é um suporte de memórias: uma afirmação que se tornou corrente entre pesquisadores de diversas áreas que se dedicam ao estudo da fotografia. No entanto, algo que parece simples a uma primeira compreensão, corre o risco de cair num vazio retórico se não for devidamente problematizado. Por um lado, a fotografia caracterizada como suporte trata unicamente do aspecto material do objeto fotografia, sem considerar que essa forma de sustentar memórias não se limita simplesmente à sua condição objetual. Por outro, o estudo das memórias sociais (coletivas ou individuais) deve considerar tanto os sistemas (mecanismos, suportes, vetores e referenciais), os conteúdos (as representações), como, também, os agentes e suas práticas.

Dessa forma, a própria experiência fotográfica já é, em si mesma, um ato de memória. Devido à sua natureza de imagem técnica, ao mesmo tempo ela cria evidências sobre o que se passou e projeta para um tempo futuro representações sobre o vivido. É, portanto, na acepção do medievalista francês Jacques le Goff, um documento-monumento, vestígio de uma prática social que se atualiza no tempo e no espaço da sua recepção e agenciamento. Desta maneira, concebida como uma dimensão da história da memória, a fotografia necessita ser avaliada por intermédio de seus suportes, das representações que produz, e dos agentes e práticas que sustentam os seus circuitos sociais.

\footnotetext{
1. Professora Associada do Departamento de História da Universidade Federal Fluminense (UFF). Pesquisadora do LABHOI-UFF e do CNPq.
} 
Vale, à título de complementação dessa breve reflexão introdutória, somente mais um comentário. Na apropriação das fotografias, inscrevem-se jogos temporais: o tempo do fotógrafo e de sua experiência; o tempo dos arquivos de sua guarda, restauro e manutenção; e o tempo do agenciamento realizado pelas pesquisas, pela análise e a posterior divulgação das imagens fotográficas em exposições, livros, artigos ou obras multimídia. $\bigcirc$ trabalho organizado e editado por Heliana Angotti-Salgueiro reúne esses três tempos de forma primorosa e, só por isso, já se constituiria numa grande contribuição para os estudos acerca da fotografia na contemporaneidade. Mas consegue ir além...

$\bigcirc$ livro, publicado em 2007, acompanha exposição realizada no mesmo ano no Museu de Arte Brasileira da FAAP. Ambos resultaram de pesquisa financiada pela The Getty Foundation, no âmbito de um Collaborative Grant Project desenvolvido pelas pesquisadoras Heliana Angotti-Salgueiro e Lygia Segala, entre junho de 2004 e dezembro de 2006, intitulado Travel images as icons of Brazil (1930s-1960s): art and visual conventions in Marcel Guatherot's photographic series. $\bigcirc$ trabalho contou com a Fundação Armando Álvares Penteado (FAAP) na gestão dos recursos e com o apoio do Instituto Moreira Salles, que disponibilizou para a pesquisa científica os acervos do fotógrafo, sob sua guarda desde 1999. O resultado desse investimento coletivo é um livro repleto de imagens - não só da autoria de Gautherot, mas também de outros fotógrafos da mesma época, cujos trabalhos foram colocados em perspectiva histórica -, acompanhado de ensaios sobre a experiência fotográfica de Gautherot, sua trajetória profissional e sua prática fotográfica.

No texto de apresentação, a organizadora da obra e curadora da exposição explica os princípios que nortearam a cenografia expositiva e as escolhas realizadas para a composição do catálogo-livro. Na apresentação, somos informados de que a exposição buscou, no processo de sua elaboração, organizar uma arqueologia das exposições fotográficas anteriores, no sentido de não somente exibir as fotografias, mas pensar o espaço expositivo como produtor de sentido histórico e social. $\bigcirc$ resultado desse investimento foi a adoção de uma mise en scène variada - escolhida em consonância com o que se queria ressaltar em cada espaço da exposição -, e, ao mesmo tempo, a criação de um elo entre as fotos e quem as contempla. Assim, como explica a curadora, a exposição"compõese em três partes: a galeria introdutória, módulo 1 e módulo 2"2.

Nesse sentido, a organização traduz para a obra impressa a perspectiva da exposição, apresentando uma divisão em dois módulos seguidos de uma conclusão que atua à maneira de um pós-escrito da exposição. $\bigcirc$ módulo 1 intitula-se Marcel Gautherot e o contexto europeu do período entre guerras, sendo composto por um introdução e seis ensaios. $\bigcirc$ módulo 2, Documentando - Brasil: Da Amazônia ao Trópico de Capricórnio, alude ao título de trabalho de Gautherot sobre suas viagens pelo Brasil (não publicado). $\bigcirc$ segundo módulo é formado por dois textos introdutórios e, também, seis ensaios temáticos.

Os ensaios de ambas as partes são assinados por seus autores, mantendo, ao mesmo tempo, a autonomia e o diálogo entre os pesquisadores. 
Nos textos, evidenciam-se as descobertas feitas durante a investigação prévia, que são compartilhadas generosamente com o leitor. Vale ressaltar que, além da riqueza e qualidade das reproduções fotográficas que acompanham os ensaios de ambas as partes, estes municiam o leitor de vasta bibliografia comentada e referências documentais preciosas, além de uma cronologia ao final do volume, constituindo-se em importante instrumento de pesquisa para futuros trabalhos.

O módulo 1, voltado para a experiência fotográfica de Gautherot antes de chegar ao Brasil, percorre o período que vai de 1925 até 1940, buscando, dentro desse limite cronológico, orientar a percepção do leitor para o olhar de Gautherot, como ele é formado, quais as características desse olho fotográfico e suas principais referências visuais. Coloca a trajetória de Gautherot na perspectiva do regime de visualidade que se conforma na primeira metade do século XX, visualidade essa definida por um conjunto variado de referências epistemológicas, estéticas e técnicas, dentre as quais destacam-se os movimentos das vanguardas artísticas (surrealismo, dadaísmo, entre outros); a perspectiva construtivista devotada à valorização das formas espaciais e à sua relação com a luz; a Nova Objetividade alemã, cujo foco recai sobre a nitidez e a acuidade visual, associadas à valorização do estilo documental, que defendia a possibilidade do registro objetivo, a valorização do corpo em movimento como a forma estética da perfeição; e, por fim, a valorização do uso etnográfico da fotografia, evidenciando um certo valor epistemológico que passa a ser atribuído à imagem como registro objetivo do mundo.

Em cada um dos ensaios desse módulo, apreendemos uma das facetas do fotógrafo e de sua rica experiência no campo da fotografia. $\bigcirc$ texto que introduz o módulo 1 justifica a escolha de voltar à Europa para poder falar da produção de Gautherot no Brasil entre 1940-1960, tema central da pesquisa. Nessa justificativa, evidencia-se que a perspectiva conceitual que orienta a obra é a de mediação, via pela qual as práticas sociais se mesclam e o aprendizado anterior informa a cada momento as novas escolhas realizadas, criando múltiplas visões num único olhar:

Embora o objetivo do projeto que resultou nesta exposição destacasse a análise das fotografias de Gautherot como "representações do Brasil moderno", sua participação na construção de convenções visuais e as modalidades de apropriação nessa linha, levando à cristalização de ícones locais, chegamos à conclusão de que não se podia ignorar seu background de experiências na Europa e dissociá-lo de sua atividade fotográfica posterior, no Brasil [...] O olho de Guatherot se formou longe daqui - composição, enquadramento e qualidade técnica independem do tema e do lugar [...] $\bigcirc$ que viria depois seria apenas uma adequação às novas condições locais, onde a luz explode o campo fotográfico, a escala assusta, a umidade e o calor exigem outros cálculos e cuidados técnicos com o material - dificuldades contornadas por aquele que já possuía o domínio da técnica, fundamental para o exercício do métier de fotógrafo ${ }^{3}$. 
Nos seis ensaios dessa primeira parte somos apresentados a Gautherot, cuja definição mais acabada é a do viajante moderno, que viaja sem bagagem, portando sua câmera compacta e um olhar treinado pela experiência moderna de objetividade, racionalidade e instantaneidade. Somos informados, no primeiro ensaio, que sua formação profissional se inicia na École nationale supérieure des arts décoratifs (ENSAD), mais voltada para uma perspectiva técnica do que a tradicional École nationale supérieure des beaux-arts. Tal treinamento o coloca em estreito contato com as perspectivas da arquitetura moderna, com Le Corbusier e a Bauhaus, inscrevendo, já na base de sua formação, o olhar plástico do arquiteto, o mais técnico dos humanistas, ou o mais humanista dos técnicos.

Nesse primeiro ensaio, também, somos informados da descoberta, importante, de que Gautherot integrou a Alliance Photo, uma das primeiras agências fotográficas francesas a defender a autoria e a autonomia do fotógrafo. grupo era devotado ao naturismo [ vida ao ar livre, ambiente natural, nudismo etc.;] e às viagens, habilitando o olhar do fotógrafo ao trânsito e ao deslocamento.

treinamento do olhar, realizado no convívio com o grupo da Alliance Photo, foi fundamental para as atividades posteriores de Gautherot, tanto em seu trabalho no Museu do Homem, em Paris (onde reuniu museografia e etnografia dentro da atividade de fotógrafo), como em suas viagens pelo México. Como integrante da equipe do Museu do Homem, conheceu outro fotógrafo francês, Pierre Verger, cuja coincidência de destinos depois os reuniria no Brasil.

Nas imagens etnográficas de Gautherot, o que se observa é o sentido de apuro técnico na busca do detalhe e na acuidade do registro. As imagens parecem saltar do quadro, efeito conseguido por uma textura especial, devida ao perfeito equilíbrio entre claros e escuros. São imagens que registram partes de um mosaico cultural formado, ainda na linha da leitura folclórica, por tipos humanos, costumes locais, detalhes de arquitetura monumental e de vegetação exótica.

De volta à França depois da viagem ao México, Gautherot participa da Exposição de Paris, de 1937, tema do quarto ensaio do módulo 1. Nessa ocasião, seu trabalho ganhou notoriedade nos círculos parisienses, apesar de não ter sido fotógrafo oficial da exposição. No entanto, a notoriedade conquistada abre espaço para a publicação de suas fotos nas revistas ilustradas Voilà, Photographie e Cahiers d'Art, como explica o quinto ensaio. As imagens publicadas foram as produzidas durante a viagem ao México, confirmando o interesse fundamental desse tipo de publicação na veiculação de imagens: "O texto explica e a foto prova" 4 . Com exceção é claro da Cahiers d'Art, voltada para a reprodução de imagens artísticas, dentre elas as dos objetos précolombianos fotografados por Gautherot em sua viagem ao México.

$\bigcirc$ módulo 1 finaliza com o ensaio intitulado Viagem moderna, uma espécie de abertura da experiência fotográfica de Gautherot para o mundo, 
complementando a vivência iniciada no México e abrindo seus olhos para novos horizontes fotográficos, dentre eles o Brasil. Entretanto, para o Brasil, não foi uma fotografia que atraiu Gautherot (e também Verger), mas um romance, Jubiabá Bahia de Todos os Santos, de autoria de Jorge Amado, traduzido para o francês em 1938. A leitura dessa obra desperta o interesse dos fotógrafos de formação etnográfica e documental pela riqueza de contrastes que o Brasil poderia revelar.

módulo 2, voltado para a experiência fotográfica de Gautherot no Brasil, entre 1940 e 1960, inicia-se com o ensaio intitulado Arquivo e coleção fotográfica, assinado por Lygia Segala. Nele, a antropóloga explica com clareza a lógica que rege o ato de arquivar e os princípios de ordenação definidos pelo próprio fotógrafo na produção de sua memória visual. $\bigcirc$ interesse recai sobre as pranchas-contato, nas quais o fotógrafo dispunha, em ordem numérica, os contatos $^{5}$ das fotografias produzidas em determinada ocasião, como forma de contar a história que vivenciou. As figuras, 172, 173 e 174 nos apresentam a seqüência completa da entrada de uma jangada no mar, com variações de ângulos e distâncias, dando movimento à narrativa visual.

segundo texto introdutório do módulo 2 - Marcel Gautherot e a foto documentária - é assinado por Heliana Angotti-Salgueiro. Nesse texto, a autora confirma sua generosidade intelectual, dividindo com os leitores informações importantes sobre a trajetória da fotografia documental. Organiza uma breve periodização, possibilitando a compreensão, dentro do panorama amplo das experiências de documentação social fotográfica, do deslocamento de Gautherot. Dessa maneira, acompanhamos as variações na trajetória profissional o fotógrafo aqui no Brasil, em sintonia com o seu tempo e suas referências visuais. Ambos os textos nos orientam pelos dois eixos que definem conceitualmente a segunda parte do trabalho: arquivo-memória; forma-conteúdo.

Os ensaios que integram o módulo 2 distribuem-se em torno de temáticas específicas: paisagem; representações do trabalho; a questão do patrimônio histórico e artístico; folclore e cultura popular; arquitetura barroca, vernacular e moderna. Somente o último (que retoma a questão da elaboração das séries, seqüências e pranchas-contatol não se organiza em torno de um tema, mas da forma de dar a ver as fotos e de arquivá-las. Nesse sentido, o módulo busca explorar os modos de atuação profissional de Gautherot, entre 1940-1960, considerando a maneira como o seu próprio arquivo foi organizado, ao mesmo tempo em que trata de dar conta das estratégias fotográficas adotadas pelo fotógrafo em cada uma das diferentes atividades a que se dedicou no Brasil. $\bigcirc$ encadeamento temático dos ensaios orienta a leitura, sem limitar a autonomia de um leitor mais disperso que, talvez, queira ler em outra ordem.

$\bigcirc$ primeiro ensaio sobre a Amazônia, apresenta Guatherot como um viajante treinado em outras paragens, mas incansável na descoberta de múltiplos "brasis" desde a Amazônia ao Trópico de Capricórnio, valorizando tanto a paisagem física, com detalhes da flora e da fauna, como a paisagem humanizada em tipos e costumes; e transformada pela ação do progresso. Essa última
5. Imagens em positivo, sem ampliação. 
6. Op. cit., fig. 192, p. 199. Fotos de 1956

7. Fotos de 1952

8. Figuras 233, 238, $239 \mathrm{e}$ 242; esta última uma bela seqüência da gestualidade da capoeira.

9. Op. cit., p. 274

10. Figuras 288 e 289. paisagem é evidenciada em uma prancha-contato 6 em que a seqüência relaciona a Cachoeira de Paulo Afonso às grandes torres de transmissão de energia.

Segue-se o ensaio Tipos e aspectos: a representação regionalizada do trabalho, que se abre com um conjunto de quatro imagens, dispostas lado a lado numa única página. Essas fotos criam um mosaico em que os tipos escolhidos por Gautherot tornam-se a síntese do Brasil profundo. Explora-se, neste ensaio, a relação entre fotografia e ilustração na figuração do mundo do trabalho, bem como o interesse etnográfico, no registro enfático que detalha o modo de operar a ferramenta de trabalho, evidenciado nas figuras 204 e 205, imagens do corte da cana-de-açúcar?

Os ensaios sobre a atuação de Gautherot no SPHAN e no registro das festas folclóricas e da cultura popular valorizam as relações que o fotógrafo estabelece com o Estado Novo, apresentando a trama histórica que sustenta sua experiência fotográfica relacionada ao patrimônio histórico e artístico. Avalia a sua relação com o Estado, com os intelectuais da época, e o papel que o SPHAN atribui à fotografia como documento e registro para ser guardado. Uma espécie de antídoto à ação do tempo e do esquecimento. No entanto, na escolha do que deveria ser fotografado, evidencia-se o que é considerado como memorável pelo próprio tempo do ato fotográfico.

Ao longo do seu trabalho no SPHAN, Gautherot fotografou com riqueza de detalhes a arquitetura colonial das cidades históricas de Minas Gerais, o seu perfil urbano e a população local. Complementando o quadro da cultura material, nele insere o universo mágico das festas populares e dos rituais folclóricos, que produziram seqüências que valorizam a cenografia própria do evento fotografado. Nelas, as diferentes opções de enquadramento, sentido e distribuição dos planos foram acionadas ora para valorizar a coreografia e os movimentos compassados do grupo, ora para caracterizar a magnitude do evento, incluindo multidões ${ }^{8}$.

Muitas vezes, o interesse do fotógrafo não era o mesmo que exigiam os protocolos definidos pelas agências oficiais incumbidas de produzir a imagem do Brasil Moderno, como informa o texto: "Gautherot fará uma declaração amarga na entrevista de 1989 a Lygia Segala, a respeito do projeto de um photo-book sobre o habitat popular que cercava a nova capital em construção: 'eu quis ir muito longe, eu quis mostrar as favelas, as cidades-satélites. Teriam a possibilidade de fazer um livro sobre Brasília com isso [...] recusaram por que era muito feio'"l'. Entretanto, com bem aponta o quinto ensaio do segundo módulo, as fotografias de Gautherot são consideradas a melhor tradução visual da nova arquitetura brasileira, cuja apoteose foi, sem dúvida, a construção de Brasília, amplamente registrada pelas lentes de Gautherot e o seu olho de arquiteto-humanista.

A sequêencia da figura 278 emblematiza tal perspectiva, pois nela os operários integram a cena evocando claramente o seu lugar de protagonista na construção da nova capital e do novo Brasil, ao menos na interpretação humanista 
do fotógrafo. Além dessa seqüência, também duas outras figuras ${ }^{10}$ denotam a metamorfose do fotógrafo em arquiteto, inserindo a própria sombra no quadro fotografado.

O último ensaio do módulo 2, de autoria de Olivier Lugon, debruça-se sobre a produção de séries, seqüências e pranchas-contato. $\bigcirc$ autor indaga as razões do fotógrafo em arquivar as seqüências:

O fato de todas as imagens da seqüência serem boas [...] e de formarem na maior parte das vezes um conjunto coerente, sem bruscos saltos geográficos ou temáticos, faz pensar que essas pranchas não são um mero decalque de negativos, mas que foram objeto de um cuidadoso trabalho de recomposição. Elas atestariam, assim, um segundo momento criativo da atividade do fotógrafo, um segundo gesto de seleção, disposição e valorização das imagens. Mas com que finalidade? Para quê? ${ }^{11}$

Na busca de uma resposta que o convença, Lugon envereda pela experiência fotográfica contemporânea à de Gautherot, indicando que a noção de seqüência era familiar à sua geração. Na continuação, discute a noção de repetição na fotografia como sendo a busca de um padrão de representação ou, ainda, de "um espírito coletivo de uma época", numa clara alusão ao Zeitgeist romântico revivido na fotografia, principalmente, naquela devotada à busca do popular ou às condições sociais da classe trabalhadora, como no caso do trabalho encetado pela Farm Security Administration (FSA)'2.

Avalia, ainda, os avanços tecnológicos que possibilitaram a produção de seqüências, mas reafirma que estas só se tornariam objeto teórico no período entre-guerras. Desse momento em diante, as séries e seqüências estariam presentes na experiência fotográfica contemporânea, evidenciando as tensões próprias da sua prática deslocando-se do singular, específico e único, para o coletivo, plural e massivo, tendo o cinema e a imagem cinética como o objeto de desejo da imagem técnica.

Lugon conclui sua reflexão encaminhando uma possível resposta à sua indagação primeira:

As pranchas-contato de Marcel Gautherot aparecem assim como o testemunho de um estado da fotografia em meados do século XX, no qual o gosto pelo transitório, pelo fragmentário e pelo múltiplo passa a conquistar amplamente o campo fotográfico, extrapolando em muito a vanguarda ou o fotojornalismo, e incluindo até a documentação etnográfica e arquitetural ${ }^{13}$.

Apesar de o fotógrafo não ter aberto mão da força de uma imagem individual, Lugon considera que, nas pranchas-contato de Gautherot, a tensão entre o exemplar único e a série fica evidente: "elas produzem sem cessar embriões de narração, esboços de passeios [...] contudo, em nenhum momento isso parece colocar em questão, para o fotógrafo, a necessidade de cada imagem poder ter vida própria"14. Assim, a forma de arquivamento em seqüência revelaria a disposição do fotógrafo em compor uma narrativa, apesar le por
11. Op. cit., p. 291.

12. A Farm Security Administration (FSA), em meados do século $\mathrm{XX}$, patrocinou um trabalho gigantesco para dar uma imagem (e uma história) à América, que resultou num arquivo fotográfico com um grande corpus (87 mil tiragens em preto e branco, montadas em cartolina, 130 mil negativos, 1.600 diapositivos Kodachrome), cujo lugar de conservação é o gabinete das gravuras da Biblioteca do Congresso, em Washington.

13. Op. cit., p. 305

14. Idem. 
15. Idem, p. 305.

16. Idem, p. 308. conta) da dimensão de corte que o ato fotográfico encerra: "Um modo de preparar seus arquivos segundo critérios que fogem da estrita lógica de ordenação, para impregná-los de um sentido suplementar que poderia, contudo, jamais sair desse porta-jóias pessoal"15.

O ensaio que conclui a obra recupera os princípios metodológicos que orientaram sua organização, enfatizando que o primeiro e o segundo módulos são dimensões da formação de um mesmo olhar - aquele que Gautherot lança sobre o Brasil, entre 1940-1960. Portanto,

partir dessa postura metodológica é considerar as experiências individuais de deslocamento [...] é repensar suas fotografias, desde as feitas no México e em Paris às inúmeras séries brasileiras, inserindo-as numa "rede de imagens". É pensar em coleções que se cruzam. Reconstituindo a historicidade das vivências profissionais de uma geração, as permanências de temáticas e os contextos plurais que as sustentam e as difundem ${ }^{16}$.

A estratégia de mapear o period eye de Gautherot em sintonia com os processos de apropriação e "olhares comuns" entre intelectuais e artistas possibilitou-me identificar, nessa trama intertextual, a presença meio velada de uma fotógrafa pouco conhecida que viajou pelo Brasil entre 1941-1942, Genevieve Naylor. Nascida nos Estados Unidos e formada em Belas Artes, quando estudante da New York School of Social Research Naylor foi aluna de Berenice Abbott. Em 1940, aos 24 anos, contratada pelo Office of Interamerican Affairs, orgão encarregado de implementar a política da Boa-Vizinhança na América Latina durante a Segunda Guerra Mundial, ela chega ao Brasil. Ao longo dos três anos que aqui viveu, morando no Rio de Janeiro, viajando pelas cidades históricas de Minas Gerais e descendo o rio São Francisco, Naylor produziu um conjunto de mais de 1.300 fotografias, das quais surge um Brasil muito, mas muito parecido com o de Gautherot.

Essa é mais uma evidência do valor da metodologia proposta pelas pesquisadoras da obra aqui resenhada, que as possibilitou descobrir intertextualidades e desvendar tramas visuais, projetando o processo criativo de Gautherot no seu tempo. Sem dúvida, uma contribuição inestimável para os estudos da fotografia contemporânea.

As imagens que integram o livro evidenciam que as escolhas editoriais, em sintonia com a perspectiva adotada na curadoria da exposição, valorizaram alguns aspectos da própria metodologia adotada: a rede visual da qual a experiência fotográfica de Gautherot foi tributária, integrando imagens de vários outros fotógrafos em perspectiva comparativa; a delimitação de temas e a escolha de imagens que emblematizassem a sua produção temática; a valorização da acuidade técnica do fotógrafo e, principalmente, a reprodução de um conjunto significativo de pranchas-contato, de valor inestimável para as pesquisas sobre a prática e a experiência da fotografia no século XX.

Concluo com um breve comentário sobre a prancha-contato final, de natureza autobiográfica, um belo e interessante exemplar de escrita auto-reflexiva 
e de construção visual do sujeito moderno. Um conjunto de visões variadas de Gautherot por ele próprio, um interessante exercício de estranhamento e projeção temporal, uma espécie de "caderno de campo" de si mesmo.

Fica evidente, na trama visual, o trabalho de memória que Gautherot realiza com a imagem fotográfica: um fragmento de tempo que ganha sentido por sua capacidade de narrar.

Resenha apresentada em 10/2008. Aprovada em 11/2008. 